and neoplasia. The inflammatory cell infiltrate present in the foci of the gastric metaplastic epithelium in lieu of the bronchial mucosa favors this hypothesis.

\section{References}

1. Marty-Ane CH, Prudhome M, Fabre JM, Domergue J, Balmes M, Mary H. Tracheoesophagogastric anastomosis fistula: a rare complication of esophagectomy. Ann Thorac Surg. 1995;60:690-3.
2. Hendren WG, Miller JI. Isolated, contained esophagobronchial fistula complicating esophagogastrectomy. Ann Thorac Surg. 1988;46:457-8.

3. Piessen G, Lamblin A, Triboulet JP, Mariette C. Peptic ulcer of the gastric tube after esophagectomy for cancer: clinical implications. Dis Esophagus. 2007;20:542-5.

4. Stal JM, Hanly PJ, Darling GE. Gastrobronchial fistula: an unusual complication of esophagectomy. Ann Thorac Surg. 1994;58:886-7.

5. Bona D, Sarli D, Saino G, Quarenghi M, Bonavina L. Successful conservative management of benign gastro-bronchial fistula after intrathoracic esophagogastrostomy. Ann Thorac Surg. 2007;84:1036-8.

\title{
Primary pulmonary meningioma: Ten-year follow-up findings for a multiple case, implying a benign biological nature
}

\author{
Yukitoshi Satoh ${ }^{\mathrm{a}, \mathrm{b}}$ and Yuichi Ishikawa, ${ }^{\mathrm{a}}$ Tokyo and Kanagawa, Japan
}

In 1998 we $^{1}$ reported the first case of multiple pulmonary meningioma, an extremely uncommon lung neoplasm. To date, there have been only 30 cases of primary pulmonary meningioma (PPM) reported in the English literature. $.^{1-3} \mathrm{Al}-$ though the lesions are widely known to be usually benign, slow growing, and to have an excellent prognosis, the etiology is still uncertain. Hence, several mechanisms have been proposed. ${ }^{1,3,4}$ We here report the clinical course of the initial case 10 years after surgery with examination by different imaging modalities and additional biopsy findings for a metachronous pulmonary lesion.

\section{CLINICAL SUMMARY}

A 74-year-old Japanese woman with a history of multiple PPM, undergoing surgery for lesions at the age of 64, was followed up by chest computed tomographic (CT) scan and magnetic resonance imaging (MRI) thereafter. During this period the patient was once referred to the Cancer Institute Hospital for percutaneous biopsy and cytologic examination of a new asymptomatic nodule that appeared in the right lower lung field 10 years after the first surgical resection (Figure 1). Histologic examination of the nodule revealed a benign PPM, which showed the same features as the lesion reported previously (Figure 2). Immunohistochemical staining performed by a standard avidin-biotin

\footnotetext{
From the Department of Pathology, ${ }^{\text {a }}$ Cancer Institute, Japanese Foundation for Cancer Research, Tokyo, and the Department of Thoracic Surgery, ${ }^{\mathrm{b}}$ Kitasato University School of Medicine, Kanagawa, Japan.

Disclosures: None.

Received for publication May 31, 2008; revisions received June 25, 2008; accepted for publication July 6, 2008; available ahead of print Dec 22, 2008.

Address for reprints: Yukitoshi Satoh, MD, Kitasato University School of Medicine, Department of Thoracic Surgery, 1-15-1 kitasato, Sagamihara-shi Kanagawa, 228-8555 Japan (E-mail: ysatoh@med.kitasato-u.ac.jp).

J Thorac Cardiovasc Surg 2010;139:e39-40

$0022-5223 / \$ 36.00$

Copyright (C) 2010 by The American Association for Thoracic Surgery

doi:10.1016/j.jtcvs.2008.07.059
}

immunoperoxidase technique demonstrated consistent expression of epithelial membrane antigen and vimentin in tumor cells. Conversely, results of studies for S-100 protein, AE1/AE3, CAM 5.2, muscle-specific actin (HHF-35), smooth muscle actin, synptophysin neuron-specific antigen, and desmin were negative. Furthermore, the tumor cells were focally positive for CD68 by KP-1 and progesterone receptor. Cytologic examination also demonstrated meningioma features, as for the lesion reported previously. ${ }^{1}$

MRI of the brain showed no abnormalities, and no intracranial or intraspinal masses were identified. On the basis of the morphologic features and the benign clinical course, the patient is being followed up by CT scan with informed consent. Although the right lung nodule has grown, the growth is very slow with a doubling time of 1011 days, the patient is asymptomatic, and there are no other new lesions in the lungs.

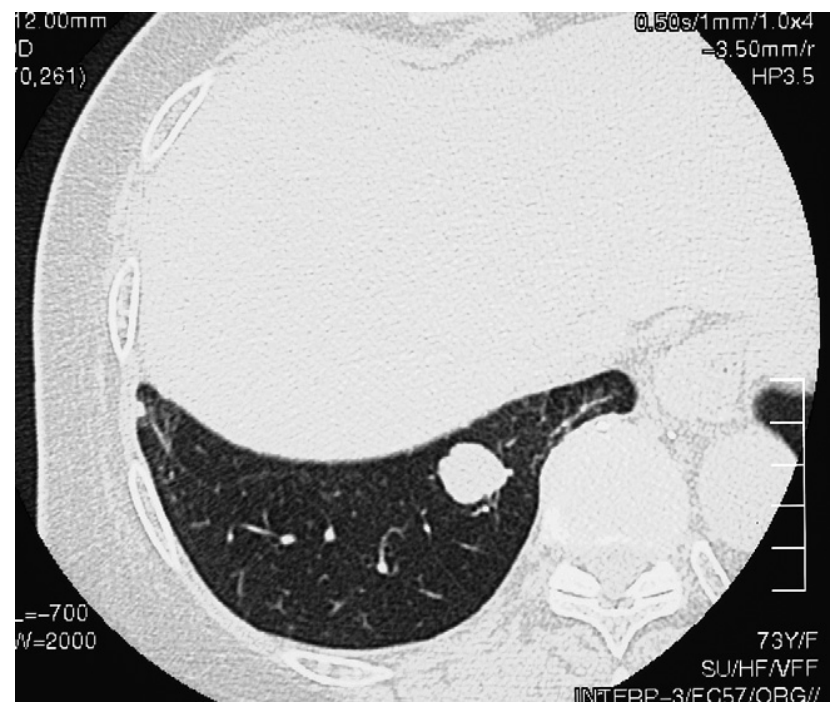

FIGURE 1. Chest computed tomographic scan showing a nodule in the right lower lung field. 


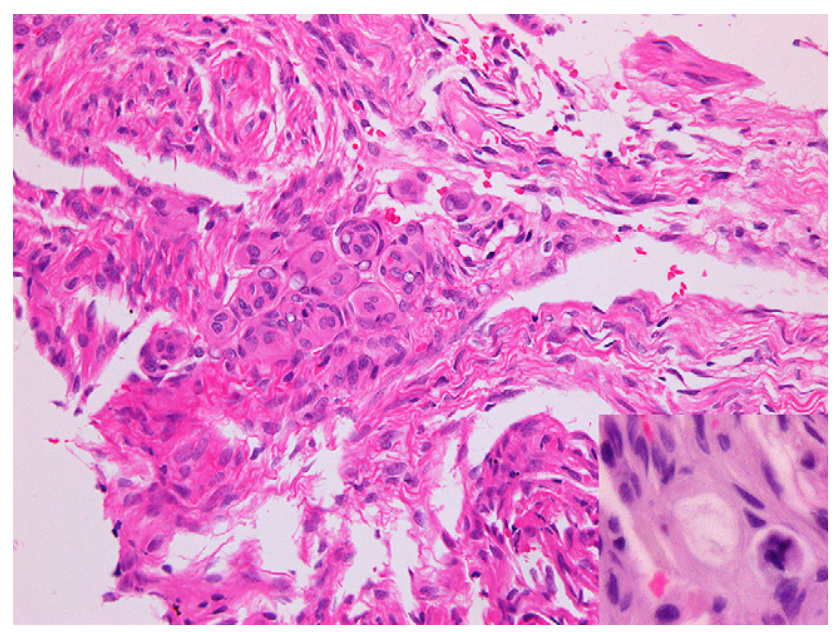

FIGURE 2. Microscopically, the nodule consists of tumor cells demonstrating a mixture of meningotheliomatous and fibrous elements (hematoxylin and eosin stain). A psammoma body is evident (islet).

\section{DISCUSSION}

We have successfully followed up the first case of multiple pulmonary meningioma by CT scan for more than 10 years after the first operation. During this period, the possibility of metastasis from an intracranial or intraspinal primary tumor was excluded by imaging modalities including CT scan and MRI. Another lesion developed in the right lung and was histologically confirmed to be meningioma, but increase in size was very slow and the lesion has remained solitary.

Immunohistochemically, the findings supported a meningothelial origin for the lesion, in line with other reports. ${ }^{1,3}$
The exact origin of meningiomas in the thorax is still debated, and different theories have been advocated, such as intrathoracic differentiation of meningocytes or arachnoid cells, ectopic proliferation of arachnoid cells, or direct/ indirect extension of primary intracranial meningiomas. ${ }^{1-4}$ In the present case, the following possibility may explain the synchronous and metachronous multiplicity: multiple pulmonary meningothelium-like nodules grew synchronously and metachronously. ${ }^{1,5}$ The tumor usually grows very slowly and patients are often free of symptoms. Even though the majority of cases demonstrate a benign behavior, the treatment usually consists of complete surgical resection. In the present case, although the new lesion demonstrated continued growth on imaging, a benign native lesion was evident on the basis of examination of a percutaneous biopsy specimen. Thus, we concluded that these tumors are amenable to surgical resection, especially in cases that prove to be benign by biopsy or cytologic examination.

\section{References}

1. Ueno M, Fujiyama J, Uchiyama T, Ishikawa Y, Satoh Y. Cytology of primary pulmonary meningioma: report of the first multiple case. Acta Cytol. 1998;42: 1424-30.

2. Meirelles GS, Ravizzini G, Moreira AL, Akhurst T. Primary pulmonary meningioma manifesting as a solitary pulmonary nodule with a false-positive PET scan. J Thorac Imaging. 2006;21:225-7.

3. Comin CE, Caldarella A, Novelli L, Janni A. Primary pulmonary meningioma: report of a case and review of the literature. Tumori. 2003;89:102-5.

4. Lockett L, Chiang V, Scully N. Primary pulmonary meningioma. Report of a case and review of the literature. Am J Surg Pathol. 1997;21:453-60.

5. Suster S, Moran CA. Diffuse pulmonary meningotheliomatosis. Am J Surg Pathol. 2007;31:624-31.

\title{
Angiosarcoma in the aortic arch presented as repeat strokes
}

\author{
Yu-Yun Nan, MD, ${ }^{\mathrm{a}}$ Yuan-Chang Liu, MD, ${ }^{\mathrm{b}}$ Ming-Shian Lu, MD, ${ }^{\mathrm{a}}$ Sui Hsueh, MD, ${ }^{\mathrm{c}}$ \\ Hsien-Kun Chang, MD, ${ }^{\mathrm{d}}$ and Yao-Kuang Huang, MD, ${ }^{\mathrm{a}, \mathrm{e}}$ Linkou, Chia-Yi, and Taipei, Taiwan
}

\footnotetext{
From the Division of Thoracic and Cardiovascular Surgery ${ }^{\mathrm{a}}$ and the Departments of Medial Image and Intervention, ${ }^{\mathrm{b}}$ Pathology, ${ }^{\mathrm{c}}$ and Oncology, ${ }^{\mathrm{d}}$ Chang Gung Memorial Hospital, and Chang Gung University, College of Medicine, Linkou and Chia-Yi, Taiwan, and the Graduate Institute of Clinical Medicines, ${ }^{\mathrm{e}}$ College of Medicine, Taipei Medical University, Taipei, Taiwan.

Disclosures: None.

Received for publication Aug 28, 2008; revisions received Sept 28, 2008; accepted for publication Oct 16, 2008; available ahead of print Feb 23, 2009.

Address for reprints: Yao-Kuang Huang, MD, Division of Cardiac Surgery, Chang Gung Memorial Hospital, Linkou, and Graduate Institute of Clinical Medicine, College of Medicine, Taipei Medical University, 5, Fu-Shin Rd, Kwei-Shan, Taoyuan, Taiwan 33377 (E-mail: huang137@mac.com).

J Thorac Cardiovasc Surg 2010;139:e40-2

$0022-5223 / \$ 36.00$

Copyright (C) 2010 Published by Elsevier Inc. on behalf of The American Association for Thoracic Surgery

doi:10.1016/j.jtcvs.2008.10.020
}

A 51-year-old man visited a local medical clinic 4 weeks before admission because of a 6-month history of weight loss and anorexia. His medical history was unremarkable except for a blood pressure discrepancy in both arms on physical examination. Furthermore, a palpable abdominal mass was found and proved later to be a probable malignant adrenal tumor by means of abdominal computed tomographic analysis.

He experienced several episodes of unconsciousness with cyanotic apnea, which required brief resuscitation and mechanical ventilator support. An unusual mass inside the innominate artery was discovered in a brain computed 